Hydrol. Earth Syst. Sci., 13, 1809-1821, 2009

www.hydrol-earth-syst-sci.net/13/1809/2009/

(C) Author(s) 2009. This work is distributed under

the Creative Commons Attribution 3.0 License.

\title{
Significance of tree roots for preferential infiltration in stagnic soils
}

\author{
B. Lange ${ }^{1,2}$, P. Lüescher ${ }^{1}$, and P. F. Germann ${ }^{2}$ \\ ${ }^{1}$ Swiss Federal Institute for Forest, Snow and Landscape Research WSL, Zuercherstrasse 111, 8903 Birmensdorf, Switzerland \\ ${ }^{2}$ Soil Science Section, Department of Geography, University of Bern, Hallerstrasse 12, 3012 Bern, Switzerland
}

Received: 21 July 2008 - Published in Hydrol. Earth Syst. Sci. Discuss.: 26 August 2008

Revised: 10 July 2009 - Accepted: 17 September 2009 - Published: 8 October 2009

\begin{abstract}
It is generally recognized that roots have an effect on infiltration. In this study we analysed the relation between root length distributions from Norway spruce (Picea abies (L.) Karst), silver fir (Abies alba Miller), European beech (Fagus sylvatica L.) and preferential infiltration in stagnic soils in the northern Pre-Alps in Switzerland. We conducted irrigation experiments $\left(1 \mathrm{~m}^{2}\right)$ and recorded water content variations with time domain reflectometry (TDR). A rivulet approach was applied to characterise preferential infiltration. Roots were sampled down to a depth of 0.5 to $1 \mathrm{~m}$ at the same position where the TDR-probes had been inserted and digitally measured. The basic properties of preferential infiltration, film thickness of mobile water and the contact length between soil and mobile water in the horizontal plane are closely related to root densities. An increase in root density resulted in an increase in contact length, but a decrease in film thickness. We modelled water content waves based on root densities and identified a range of root densities that lead to a maximum volume flux density and infiltration capacity. These findings provide convincing evidence that tree roots in stagnic soils represent the pore system that carries preferential infiltration. Thus, the presence of roots should improve infiltration.
\end{abstract}

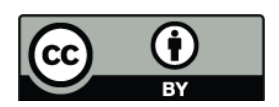

Correspondence to: $\mathrm{B}$. Lange

(benjamin.lange@wsl.ch)
Abbreviations
$F \quad$ arithmetic mean of film thickness of mobile water $\left(10^{-6} \mathrm{~m}\right)$
$L \quad$ maximal sum of contact length between mobile water and soil $\left(10^{3} \mathrm{~m} \mathrm{~m}^{-2}\right)$
RA root surface area per soil volume $\left(\mathrm{cm}^{2} \mathrm{~cm}^{-3}\right)$
RL root length per soil volume $\left(\mathrm{cm} \mathrm{cm}^{-3}\right)$
$\mathrm{RV}$ root volume per soil volume $\left(\mathrm{cm}^{3} \mathrm{~cm}^{-3}\right)$

\section{Introduction}

The impact of forests on reducing surface runoff has been a subject of study in Europe for over 100 years (e.g. Demontzey, 1878; Engler 1919). It has been addressed on various spatial scales, especially with regard to the effect of clear cutting on peak flow (e.g. Beschta et al., 2000; Cheng et al., 2002; Tremblay et al., 2008). For example, Cognard-Plancq et al. (2001) claimed that forest-covered soils can store more water than soils without trees. Water storage depends not only on the percentage of forested area, but also on the forest site in a catchment area, as different sites influence infiltration capacities differently (Badoux et al., 2006). Hegg et al. (2004) showed that water storage capacities vary depending on the type of forest site. For example, the forest site type Bazzanio-Abietetum (Ellenberg and Klötzli, 1972) comprises a wide range of infiltration capacities, which are also determined by the condition of the forest: the closer the forest is to its natural stage, the higher is its corresponding infiltration capacity.

Macropores, which are large continuous openings formed by soil fauna, freeze/thaw cycles, shrinking processes, subsurface erosion or plant roots (Beven and Germann, 1982), are assumed to increase infiltration rates and thus preferential

Published by Copernicus Publications on behalf of the European Geosciences Union. 
flow (Mapa, 1995). Preferential flow is characterised by a non-homogenous movement of water through soils (Gish et al., 1998). Three main types of preferential infiltration have been identified: bypass flow (Beven and Germann, 1982; Bouma, 1991), finger flow in structureless, sandy soils (e.g. Kawamoto et al., 2004), and funnel flow (Kung, 1990). To describe preferential flow in structured soils, various models of preferential infiltration have been proposed, since the application of Richards' equation (1931) is rather limited (Gerke, 2006). Under conditions of near saturation, preferential flow has been described in two different ways (Germann et al., 2007). The first is to approach the expected preferential flow from Richards' domain. Gärdenäs et al. (2006), for example, applied Richards' equation to four approaches, including one equilibrium and three non-equilibrium approaches, and implemented them in the HYDRUS-2D twodimensional model.

The second way deduces preferential flow from freesurface flow. Germann and Beven (1985) approached preferential flow using kinematic wave theory, including a sink function for macropore flow to take account of sorption by the surrounding matrix. Many authors have adapted the kinematic wave approach. Di Pietro et al. (2003), for example, described preferential flow by a travelling-dispersive wave, which yields a linear solution of a non-linear convectivedispersive equation. Germann et al. (2007) proposed a rivulet approach to preferential infiltration. The approach is based on the assumption that gravity is the only flow-driving force and viscosity is the only force that opposes gravity. Tiny water streaks, termed rivulets, are the basic units of preferential infiltration. Film thickness $F(\mathrm{~m})$ and length of contact $L$ $\left(\mathrm{m} \mathrm{m}^{-2}\right)$ in the horizontal plane with the stationary parts are the basic properties of a rivulet. The velocities of the wetting and drainage fronts, the mobile water content and the volume flux density of drainage are linked to the rivulet's basic properties. In this paper, the rivulet approach is used to characterise preferential flow.

Although the notion that roots influence preferential flow is widespread, root parameters have seldom been recorded in relation to preferential flow. The roots of corn (Zea mays) and alfalfa (Medicago sativa) are able to form wellconnected macropores that enhance preferential flow. Furthermore, the saturated hydraulic conductivity $\left(K_{s m}\right)$ in soil columns with root channels was six times higher than in control columns without roots ( $\mathrm{Li}$ and Ghodrati, 1994). Jøergensen et al. (2002) found that $94 \%$ of flow in a clayrich till was conducted along root channels, while only 6 $\%$ flowed along fractures without root channels. Numerous studies have visualised preferential flow paths by staining (e.g. Alaoui and Goetz, 2008; Weiler and Naef, 2003). Roots, decayed or live, appear to be the most important agents of preferential flow paths, but not all roots are necessarily associated with them (Perillo et al., 1999). Hegg et al. (2004) claimed that tree roots are able to penetrate into stagnic horizons and may enlarge the pore system and hence infiltrability.
Accordingly, the objective of this study is to use the rivulet approach (Germann et al., 2007) to identify the relation between root distribution and preferential flow in stagnic soils.

\section{Theory}

Infiltration at the surface is considered a rectangular pulse of duration $T_{S}$ (s) and volume flux density $q_{S}\left(\mathrm{~m} \mathrm{~s}^{-1}\right)$. It releases a water content wave wcw at the beginning of water input at time $t=0(\mathrm{~s})$. A rivulet is the basic unit of a wcw. It is a tiny streak of water that is gravity-driven and viscositycontrolled. It is, however, too tiny to be measured in situ with ordinarily applied instrumentation, such as TDR- equipment. All the rivulets moving with the same velocity are summarized as a rivulet ensemble whose mobile water content is measurable in situ. Superposition of all rivulet ensembles adds up to the entire wcw. A rivulet ensemble consists of a water film that is defined with its thickness $F(\mathrm{~m})$ and length of contact $L(\mathrm{~m})$ per $A\left(\mathrm{~m}^{2}\right)$ of the ensemble with the stationary parts of the soil-water system, where $A$ is the crosssectional area of soil. The $j$ th ensemble's wetting and draining fronts arrive at depth $Z(\mathrm{~m})$ at times $t_{w, j}(Z)$ and $t_{D, j}(Z)$, where $1 \leq j \leq N_{\mathrm{RE}}$. The following expressions quantify flow. The mobile water content of the $j$ th rivulet ensemble, $w_{j}$, can be calculated as:

$w_{j}=L_{j} \cdot F_{j}$

$\left(\mathrm{m}^{3} \mathrm{~m}^{-3}\right)$, the average velocity of the film, $v_{j}$, is given by:

$v_{j}=\frac{g}{3 \eta} F_{j}^{2}$

$\left(\mathrm{m} \mathrm{s}^{-1}\right)$, where $g\left(=9.81 \mathrm{~m} \mathrm{~s}^{-2}\right)$ is acceleration due to gravity and $\eta\left(=10^{-6} \mathrm{~m}^{2} \mathrm{~s}^{-1}\right)$ is the kinematic viscosity of water. An ensemble's volume flux density, $q_{j}$, is given as:

$q_{j}=w_{j} \cdot v_{j}=\frac{g}{3 \eta} F_{j}^{3} L_{j}$

Knowing any two of the three variables, $w, v$ and $q$ suffices to define an ensemble's $F$ and $L$, and subsequently the third expression (see Germann et al., 2007). The arrival time of the $j$ th ensemble's wetting front, $t_{w, j}$ (s), at a depth $Z$ is:

$t_{w, j}(Z)=\frac{Z}{v_{j}}=\frac{Z}{F_{j}^{2}} \frac{3 \eta}{g}$

and the arrival time of the drainage front, $t_{D, j}(\mathrm{~s})$, is given as:

$t_{D, j}(Z)=T_{S}+\frac{t_{w, j}(Z)}{3}$

The combination of Eqs. (2) and (4) leads to the ensemble's film thickness $F_{j}$ :

$F_{j}=\frac{1}{\sqrt{t_{w, j}(Z)}} \sqrt{\frac{3 Z \eta}{g}}=\sqrt{\frac{3 v_{j} \eta}{g}}$ 


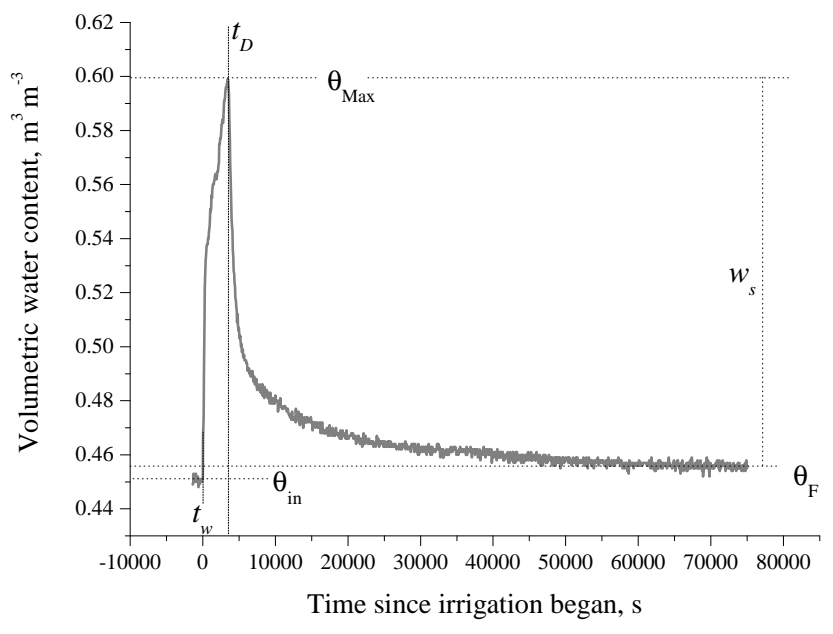

Fig. 1. Definitions of parameters and variables of a water content wave (wcw), shown for ID\# 19 (according to Table 2), depth $0.04 \mathrm{~m}$. $t_{w}$ : arrival time of first measurable moisture increase; $t_{D}$ : arrival time of drainage front; $\theta_{\text {in }}$ : initial volumetric soil moisture; $\theta_{\mathrm{Max}}$ : maximum volumetric soil moisture; $\theta_{\mathrm{F}}$ : final volumetric soil moisture after a drainage of $20 \mathrm{~h} ; w_{s}: \theta_{\mathrm{Max}}-\theta_{\mathrm{F}}$, amplitude of moisture wave.

and the combination of Eqs. (1) and (6) results in the ensemble's contact length, $L_{j}$, with stationary parts per $A$ expressed as:

$L_{j}=w_{j} \sqrt{\frac{t_{w, j}(Z) g}{3 Z \eta}}$

The mobile water content of the $j$ th ensemble's trailing wave, $\omega_{j}(Z, t)$, at depth $Z$ and $t \geq t_{D, j}$ is:

$\omega_{j}(Z, t)=\left(t-T_{S}\right)^{-0.5}\left(L_{j} F_{j}\right)\left(t_{D, j}(Z)-T_{S}\right)^{0.5}$

A wcw is composed of $N_{\mathrm{RE}}$ rivulet ensembles. The sum of contact lengths, $L$, per $A$ is:

$L=\sum_{j=1}^{N_{\mathrm{RE}}} L_{j}$

and an entire wcw's average film thickness, $F$, is given as:

$F=\frac{\sum_{j=1}^{N_{\mathrm{RE}}} F_{j}}{N_{\mathrm{RE}}}$

Superimposing the trailing waves at $t \geq t_{D}$ of $N_{\mathrm{RE}}$ rivulet ensembles results in the entire wcw's trailing wave, $\omega_{e n}(Z, t)$ at depth $Z$ as:

$\omega_{e n}(Z, t)=\left(t-T_{S}\right)^{-0.5} \sum_{j=1}^{N_{\mathrm{RE}}}\left(L_{j} F_{j}\right)\left[t_{D, j}(Z)-T_{S}\right]^{0.5}$

The interpretation of a time series $\theta(Z, t)$ shown in Fig. 1 is according to the following 7-point protocol adapted from Germann et al. (2007):

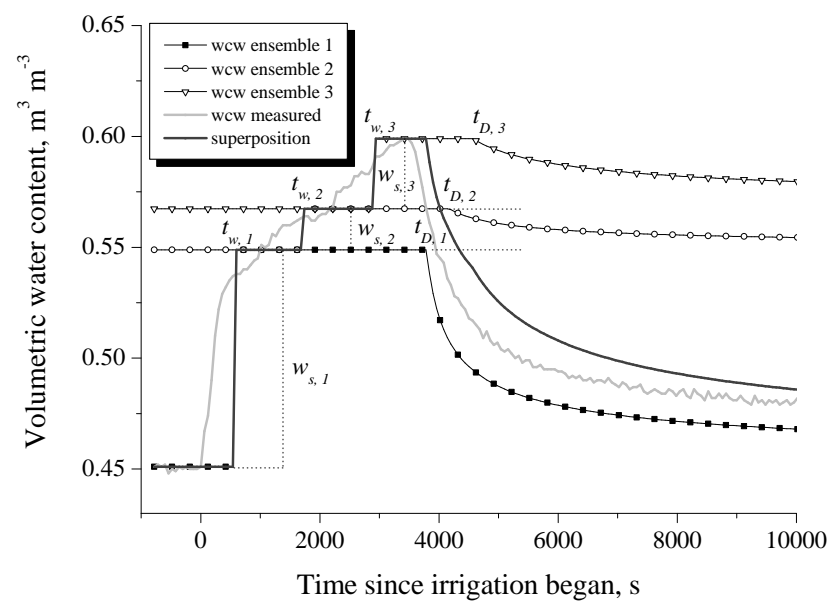

Fig. 2. Superposition of three rivulet ensembles applied to data of ID\# 19 (according to Table 2). wcw: water content wave; $t_{w, j}$ : arrival time of first measurable moisture increase of the $j$ th rivulet ensemble; $t_{D, j}$ : arrival time of drainage front of the $j$ th rivulet ensemble; $w_{s, j}$ : amplitude of moisture wave of the $j$ th rivulet ensemble.

1. Determine final volumetric soil moisture $\theta_{\mathrm{F}}$ (Fig. 1).

2. Subtract $\theta_{\mathrm{F}}$ from $\theta(Z, t)$, which results in the mobile water content $w(Z, t)$.

3. Partition the time period between the beginning of the irrigation at $t_{0}$ and the time when the soil moisture become steady into $N_{R}=10$ rivulet ensembles, and estimate the corresponding mobile water content $w_{j}$ of each rivulet ensemble (Eq. 1).

4. Assign arrival times of the wetting fronts, $t_{w, j}(Z)$, to each rivulet ensemble (Fig. 2).

5. The rivulets' film thickness, $F_{j}$, Eq. (6), and the contact lengths per area, $L_{j}$, Eq. (7) can be derived from the arrival times of the wetting fronts

6. Calculate the entire wcw's contact length $L$ (Eq. 9) and the average film thickness $F$ (Eq. 10)

Figure 2 illustrates the procedure with $N_{\mathrm{RE}}=3$. Figure 3 shows the application of the rivulet approach to a measured wcw. The comparison of the performance of Eq. (11) with the data of the trailing wave of a wcw gives an independent measure of the adequacy of the rivulet approach. The coefficient of determination between approach and data in Fig. 3 was $R^{2}=0.983$.

\section{Site, materials and methods}

\subsection{Site and soil description}

The study area is located near Rueschegg in Canton Bern in the northern Pre-Alps in Switzerland $\left(46^{\circ} 46^{\prime} \mathrm{N}, 7^{\circ} 23^{\prime} \mathrm{E}\right.$, 


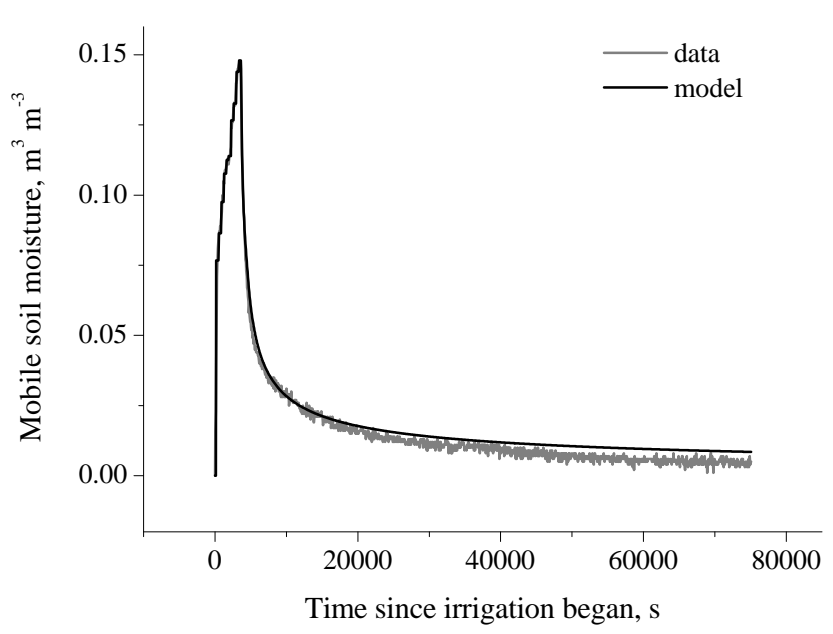

Fig. 3. Ten rivulet ensembles applied to data of the third irrigation of ID\# 19 (according to Table 2) at a depth of $0.04 \mathrm{~m}$. Comparison of superimposed trailing wave with measured data.

$1000 \mathrm{~m}$ a.s.1). Annual mean precipitation is approximately $1700 \mathrm{~mm}$. The bedrock consists of Flysch, a sediment of the tertiary, composed of marled clays interlaced with stony or sandy layers. The stand is classified as a BazzanioAbietetum (Ellenberg and Klötzli, 1972) with Norway spruce (Picea abies (L.) Karst.) as the most abundant species mixed with silver fir (Abies alba Miller) and a few solitary European beech (Fagus sylvatica L.). Whortleberry (Vaccinium myrtillus) dominates the herb and shrub layer.

The region where the study was conducted has been frequently affected by floods in the last twenty years (1990, 2005 and 2007, Federal Office for the Environment, 2008), due to high levels of precipitation and the hydromorphic soils. The soils are classified as Gleys, Cambisols and gleyic or stagnic Cambisols, according to FAO-Unesco (1994). Local ridges and depressions characterise the micro-topography on a scale of 1 to $10 \mathrm{~m}$. Hydromorphic characteristics occur below a depth of 3 to $35 \mathrm{~cm}$, depending on the microtopography. As a consequence, the maximum root depths, especially those of spruce and beech, are limited. Thirteen plots were investigated. They differ with respect to the species, tree diameters and the distances between the tree trunks and the plots. Table 1 lists the attributes of each plot. The slopes of the plots are between 0 and $14^{\circ}$.

Soil properties were determined from samples dried for $48 \mathrm{~h}$ at $105^{\circ} \mathrm{C}$ for density and at $60^{\circ} \mathrm{C}$ for $\mathrm{pH}$ and texture. Three cylinders per horizon, $1000 \mathrm{~cm}^{3}$ in volume and $10 \mathrm{~cm}$ in height, were used to calculate the bulk density. Porosity was calculated from the bulk density, assuming a particle density of $2650 \mathrm{~kg} \mathrm{~m}^{-3}$. The particle-size distribution separation was obtained with the pipette method. Table 1 lists the soil properties. The $\mathrm{pH}\left(\mathrm{CaCl}_{2}\right)$ varies between 2.8 and 6.6 in the topsoil and between 3.1 and 7.5 in the mineral layer. Bulk densities vary from 0.19 to $1.01 \mathrm{Mg} \mathrm{m}^{-3}$ in the organic and Ah-horizons and from 1.21 to $1.43 \mathrm{Mg} \mathrm{m}^{-3}$ in the subsoil. Thus, root growth is not limited by soil compaction (Polomski and Kuhn, 1998). The particle size distributions vary over a considerable range. The Ah-horizons consist of loam, clay loam, sandy loam or sandy clay loam, and the mineral horizons of loam, sandy clay loam, sandy clay or clay. Most of the horizons investigated had blocky structure. Only three were single grained and one was massive (Soil survey division staff, 1993). Detailed descriptions of chemical and physical properties of a soil at the investigated area are given in Zimmermann et al. (2006).

The basic units for the investigation were the morphological horizons. The root-length density and the chemical, physical, and hydrological parameters refer to the morphological horizons. There was a data set available for each horizon, consisting of water content measurements, root-length density and the physical and chemical soil parameters.

\subsection{Instrumentation and infiltration experiments}

Soil moisture was measured with TDR-probes. The wave guides consisted of two paired, $0.15 \mathrm{~m}$ long stainless steel rods, $30 \mathrm{~mm}$ apart and $5 \mathrm{~mm}$ in diameter. The rods were electrically connected with a $50 \Omega$ coax cable to a SDMX 50 coaxial multiplexer, which was controlled by a CR10X micro logger. The electrical pulses were generated by a Campell TDR100 device which also received the signals. The measurement interval was set to $60 \mathrm{~s}$. We applied the transfer function of Roth et al. (1990) to calculate the volumetric water content. Prior to the installation, the TDR probes were calibrated by submerging each wave-guide. The corresponding dielectric number was set equal to the volumetric water content of $1 \mathrm{~m}^{3} \mathrm{~m}^{-3}$. For the installation of the wave- guides, soil profiles were excavated. The TDR-probes were installed horizontally at the centre of each horizon.

The rain simulator consisted of a metallic plate $(1 \mathrm{~m} \times 1 \mathrm{~m})$ that was perforated with 100 holes attached to small tubes with inner diameters of $2 \mathrm{~mm}$ that led to a reservoir. The tubes were mounted in a $0.1 \times 0.1 \mathrm{~m}$ square pattern. During irrigation, a motor moved the plate backwards and forwards $\pm 50 \mathrm{~mm}$ in both horizontal dimensions, so that it took approximately $1800 \mathrm{~s}$ until a tube reached to exactly the same position. The intensity of the irrigation was controlled by a flow meter. The distances between the metallic plate and the soil surface were between 0.3 and $0.5 \mathrm{~m}$. During the experiment, the $1 \mathrm{~m}^{2}$ irrigated area was covered with a waterproof $3 \times 3 \mathrm{~m}$ tent in order to protect the set-up and the soil from precipitation. Each plot was irrigated three times for one hour at approximately $23 \mathrm{~h}$ intervals. The volume flux density of irrigation was $70 \mathrm{~mm} / \mathrm{h}$, which is the annual hourly maximum for this region with return periods of approximately 100 years. The rates never resulted in surface runoff. 
Table 1. Characteristics of the irrigated plots.

\begin{tabular}{|c|c|c|c|c|c|c|c|c|c|c|c|}
\hline \multirow[t]{2}{*}{ Site } & \multirow[t]{2}{*}{$\begin{array}{l}\text { Tree diameter } \\
\mathrm{cm}\end{array}$} & \multirow[t]{2}{*}{$\begin{array}{l}\text { Distance to } \\
\text { stem, } \mathrm{m}\end{array}$} & \multirow[t]{2}{*}{ Soil type $^{\mathrm{a}}$} & \multicolumn{2}{|c|}{$\begin{array}{c}\mathrm{pH} \mathrm{CaCl} \mathrm{Ca}_{2} \\
\text { (range) }\end{array}$} & \multicolumn{2}{|c|}{ Texture $^{\mathrm{b}}$} & \multicolumn{2}{|c|}{$\begin{array}{c}\text { Average bulk } \\
\text { density, } \mathrm{Mg} \mathrm{m}^{-3}\end{array}$} & \multicolumn{2}{|c|}{$\begin{array}{c}\text { Average Porosity } \\
\mathrm{m}^{3} \mathrm{~m}^{-3}\end{array}$} \\
\hline & & & & $\mathrm{T}$ & $\mathrm{S}$ & $\mathrm{T}$ & $\mathrm{S}$ & $\mathrm{T}$ & $\mathrm{S}$ & $\mathrm{T}$ & $\mathrm{S}$ \\
\hline Spruce 1 & 60 & 1 & Gleyic Cambisol & $6.2-6.3$ & $6.2-6.9$ & Clay loam & Clay loam & 0.85 & 1.25 & 0.68 & 0.53 \\
\hline Spruce 2 & 80 & 3.7 & Mollic Gley & 6.2 & $6.2-7.4$ & Clay loam & Clay loam & 0.73 & 1.31 & 0.72 & 0.51 \\
\hline Spruce 3 & 7 & 1 & Mollic Gley & $3.0-3.2$ & $3.3-4.1$ & Sandy loam & Loam & 0.99 & 1.35 & 0.63 & 0.49 \\
\hline Fir 1 & 65 & 1 & Gleyic Cambisol & $3.1-3.8$ & $3.4-6.1$ & Sandy clay loam & Clay loam & 0.19 & 1.35 & 0.92 & 0.49 \\
\hline Fir 2 & 33 & 1 & Gleyic Cambisol & 3.4 & $3.6-6.2$ & Sandy loam & Loam & 0.88 & 1.43 & 0.67 & 0.46 \\
\hline Fir 3 & 35 & 1 & Eutric Cambisol & $2.9-3.6$ & $3.3-3.7$ & Sandy loam & Clay loam & 0.94 & 1.29 & 0.65 & 0.51 \\
\hline Fir 4 & 65 & 3.2 & Mollic Gley & 6.6 & $6.4-7.4$ & Loam & Clay loam & 0.70 & 1.34 & 0.73 & 0.49 \\
\hline Fir 5 & 18 & 1 & Mollic Gley & $2.8-3.1$ & $3.1-7.5$ & Sandy clay loam & Loam & 0.63 & 1.38 & 0.76 & 0.48 \\
\hline Beech 1 & 40 & 1 & Gleyic Cambisol & $2.9-3.4$ & $3.5-6.2$ & Sandy clay loam & Sandy clay loam & 0.62 & 1.42 & 0.76 & 0.46 \\
\hline Beech 2 & 40 & 1 & Gleyic Cambisol & $2.9-3.4$ & $3.5-6.2$ & Sandy clay loam & Sandy clay loam & 0.62 & 1.42 & 0.76 & 0.46 \\
\hline Beech 3 & 46 & 3.5 & Mollic Gley & 6.4 & $6.7-7.4$ & Clay loam & Clay & 0.72 & 1.26 & 0.73 & 0.52 \\
\hline Beech 4 & 13 & 1.5 & Stagnic Cambisol & $3.1-3.5$ & $3.3-3.8$ & Sandy loam & Clay loam & 1.01 & 1.21 & 0.61 & 0.54 \\
\hline Beech 5 & 3 & 1 & Gleyic Cambisol & $3.0-3.8$ & $3.5-4.8$ & Sandy loam & Clay loam & 0.75 & 1.30 & 0.71 & 0.51 \\
\hline
\end{tabular}

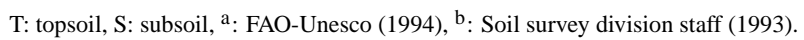

\subsection{Root distribution}

Each plot was sampled after irrigation with soil cores $5 \mathrm{~cm}$ away from the profile face, exactly in the same place where the TDR probes had been installed. Soil cores were taken with a HUMAX soil corer (diameter $10 \mathrm{~cm}$ ) to depths between 0.5 and $1 \mathrm{~m}$, depending on the location of the lowest TDR probe. The probes consisted of $25 \mathrm{~cm}$ long segments in plastic tubes. The soil was left undisturbed during sampling and storage (in a refrigerator at $4^{\circ} \mathrm{C}$ for no longer than 12 weeks). Each core segment was separated along the boundaries of the horizons into different layers that were analyzed separately.

The roots were sieved and washed in a $1 \mathrm{~mm}$ sieve with tap water. All root fragments (woody and herb roots) were collected and stored at $4{ }^{\circ} \mathrm{C}$. The roots were analyzed with WinRhizo (V4.1c; Regent Instruments Inc., Quebec, Canada). We recorded root length $(\mathrm{cm})$, surface area $\left(\mathrm{cm}^{2}\right)$, diameter $(\mathrm{cm})$ and volume $\left(\mathrm{cm}^{3}\right)$. Each parameter was calculated for the total root sample and for fine $(\varnothing \leq 2 \mathrm{~mm})$ and coarse roots $(\varnothing>2 \mathrm{~mm})$ separately.

\section{Results}

\subsection{Hydrological parameters}

A total of 225 water content waves, wcw, from 75 horizons were recorded with the TDR-equipment. The coefficient of determination, $R^{2}$, between the measured and modelled wcw exceeded 0.70 in only 21 horizons ( 49 water content waves), where we assume preferential infiltration according to Eqs. (1) to (11). The remaining 54 horizons showed perched water tables due to the impermeable soil layers, which contradict the conditions of rivulet flow. Since the aim of this study was to explore the relevance of tree roots for preferential infiltration, we included only the 49 water content waves in the further analyses.

Each of the 21 horizons showed a coefficient of determination $R^{2} \geq 0.70$ between measured and modelled wcw during two or three of the three irrigations. For each horizon, we considered the wcw with the best correlation between the measured and calculated trailing waves (according to Eq. 11), which resulted in a data-base consisting of the rootlength density and associated soil moisture recordings from 13 different soil profiles and of 21 morphological horizons.

Table 2 lists the key points in the measured time series of volumetric water content $\theta(Z, t)$. The arithmetic mean of the 21 amplitudes, $w_{s}$, was $0.072 \mathrm{~m}^{3} \mathrm{~m}^{-3}$ ranging between 0.021 and $0.143 \mathrm{~m}^{3} \mathrm{~m}^{-3}$. The velocity of a wetting front follows from:

$v_{w}=\frac{Z}{t_{w}}$

The velocities were between 0.11 and $1.11 \mathrm{~mm} \mathrm{~s}^{-1}$ and compare well with those measured by Germann and Hensel (2006), which were between 0.1 and $5.5 \mathrm{~mm} \mathrm{~s}^{-1}$. Volume flux density $q$, according to Eq. (3), was between 1.69 and $31.8 \times 10^{-6} \mathrm{~m} \mathrm{~s}^{-1}$. Adoption of Eq. (6) produced an estimate of the rivulet's film thickness. The arithmetic mean of the ten film thicknesses, which formed the increasing limb of the soil moisture wave (Fig. 3), is the wave's overall film thickness $F$ (Eq. 10). The thinnest film was 4.2, and the thickest $18.1 \mu \mathrm{m}$. The maximum sum of the contact lengths $L$, according to Eq. (9), varied between 1448 and $25116 \mathrm{~m} \mathrm{~m}^{-2}$ for the 21 wcws.

\subsection{Root distribution}

Root distribution was determined in each morphological horizon that produced a wcw. The root distributions of the tree species were not distinguishable according to soil depth 
Table 2. Key points in the measured time series of preferential infiltration.

\begin{tabular}{|c|c|c|c|c|c|c|c|c|c|c|}
\hline ID\# & Site & $\begin{array}{l}\text { Depth of TDR } \\
m\end{array}$ & $\theta_{\text {in }} \mathrm{m}^{3} \mathrm{~m}^{-3}$ & $\begin{array}{l}\theta_{\mathrm{Max}} \\
\mathrm{m}^{3} \mathrm{~m}^{-3}\end{array}$ & $\begin{array}{l}\theta_{\mathrm{F}} \\
\mathrm{m}^{3} \mathrm{~m}^{-3}\end{array}$ & $\begin{array}{l}w_{s} \\
\mathrm{~m}^{3} \mathrm{~m}^{-3}\end{array}$ & $\begin{array}{l}q \\
10^{-6} \mathrm{~ms}^{-1}\end{array}$ & $\begin{array}{l}v_{w} \\
\mathrm{mms}^{-1}\end{array}$ & $\begin{array}{l}L \\
10^{3} \mathrm{~m} \mathrm{~m}^{-2}\end{array}$ & $\begin{array}{l}F \\
\mu \mathrm{m}\end{array}$ \\
\hline 1 & Spruce 1 & 0.12 & 0.301 & 0.424 & 0.321 & 0.103 & 12.88 & 0.22 & 12.982 & 6.5 \\
\hline 2 & Spruce 2 & 0.05 & 0.473 & 0.546 & 0.465 & 0.081 & 19.24 & 0.83 & 8.072 & 10.4 \\
\hline 3 & Spruce 3 & 0.05 & 0.369 & 0.506 & 0.369 & 0.137 & 14.42 & 0.41 & 15.683 & 7.2 \\
\hline 4 & Spruce 3 & 0.2 & 0.443 & 0.526 & 0.442 & 0.084 & 31.01 & 1.11 & 5.342 & 14.0 \\
\hline 5 & Fir 1 & 0.04 & 0.244 & 0.372 & 0.245 & 0.127 & 12.09 & 0.17 & 24.489 & 4.5 \\
\hline 6 & Fir 1 & 0.24 & 0.388 & 0.441 & 0.389 & 0.052 & 18.01 & 0.8 & 3.508 & 12.4 \\
\hline 7 & Fir 1 & 0.45 & 0.359 & 0.388 & 0.366 & 0.022 & 6.36 & 0.47 & 1.846 & 11.9 \\
\hline 8 & Fir 2 & 0.04 & 0.408 & 0.467 & 0.419 & 0.048 & 3.05 & 0.17 & 9.647 & 4.2 \\
\hline 9 & Fir 2 & 0.17 & 0.406 & 0.444 & 0.413 & 0.031 & 11.74 & 0.57 & 2.546 & 10.7 \\
\hline 10 & Fir 3 & 0.26 & 0.357 & 0.404 & 0.373 & 0.031 & 3.44 & 0.18 & 3.837 & 8.0 \\
\hline 11 & Fir 3 & 0.42 & 0.442 & 0.504 & 0.448 & 0.056 & 31.8 & 10 & 3.251 & 18.1 \\
\hline 12 & Fir 4 & 0.06 & 0.445 & 0.583 & 0.446 & 0.137 & 18.69 & a) & 18.922 & 6.1 \\
\hline 13 & Fir 5 & 0.17 & 0.471 & 0.56 & 0.508 & 0.052 & 4.16 & 0.11 & 6.034 & 7.2 \\
\hline 14 & Fir 5 & 0.23 & 0.501 & 0.55 & 0.499 & 0.051 & 14.33 & 0.95 & 4.163 & 12.8 \\
\hline 15 & Beech 1 & 0.05 & 0.295 & 0.424 & 0.293 & 0.131 & 9.12 & 0.17 & 18.579 & 5.7 \\
\hline 16 & Beech 1 & 0.18 & 0.427 & 0.482 & 0.427 & 0.055 & 9.45 & 0.25 & 4.831 & 10.5 \\
\hline 17 & Beech 2 & 0.08 & 0.428 & 0.52 & 0.434 & 0.086 & 1.69 & 0.66 & 9.102 & 9.2 \\
\hline 18 & Beech 2 & 0.18 & 0.432 & 0.473 & 0.438 & 0.035 & 4.46 & 0.15 & 3.166 & 9.1 \\
\hline 19 & Beech 3 & 0.04 & 0.451 & 0.599 & 0.456 & 0.143 & 19.9 & a) & 25.116 & 4.8 \\
\hline 20 & Beech 4 & 0.65 & 0.371 & 0.413 & 0.385 & 0.028 & 9.04 & 0.43 & 1.905 & 14.0 \\
\hline 21 & Beech 5 & 0.45 & 0.477 & 0.503 & 0.482 & 0.021 & 8.01 & 0.68 & 1.448 & 13.6 \\
\hline
\end{tabular}

Depth of TDR: position of TDR-probe beneath soil surface; $\theta_{\text {in }}$ : initial volumetric soil moisture; $\theta_{\text {Max }}$ : maximum volumetric soil moisture; $\theta_{\mathrm{F}}$ : volumetric water content after a drainage of $20 \mathrm{~h} ; \mathrm{w}_{s}$ : difference between $\theta_{\mathrm{Max}}$ and $\theta_{\mathrm{F}} ; q$ : volume flux density; $v_{w}$ : average velocity of wetting front; $L$ : maximal sum of contact lengths between the mobile water and soil for $\theta(Z, t) \geq \theta_{\mathrm{F}} ; F$ : arithmetic mean of film thickness of mobile water for $\theta(Z, t) \geq \theta_{\mathrm{F}}$. a): No data available as $t_{w}=0$.

in terms of the lengths of the fine roots $(\leq 2 \mathrm{~mm})$ and coarse roots $(>2 \mathrm{~mm}$ ) or the total root length (one way ANOVA, $P<0.05)$. The median of fine root lengths per soil volume $\left(0.064 \mathrm{~cm} \mathrm{~cm}^{3}\right)$, including all species and soil depths, was about one order of magnitude higher than the median of coarse root lengths $\left(0.005 \mathrm{~cm} \mathrm{~cm}^{-3}\right)$.

Figure 4 gives an overview of root lengths per soil volume.

The variation in root lengths per soil volume (RL) was considerable, exhibiting values between 0.023 and $2.216 \mathrm{~cm} \mathrm{~cm}^{-3}$. The RL of spruce, fir and beech reached the maximum lengths in topsoil, with roots from the root diameter classes of $0.5-1$ and $1-1.5 \mathrm{~mm}$ (Fig. 4). The arithmetic means of root surface areas per soil volume (RA) did not significantly differ (one way ANOVA, $P<0.05$, not shown) according to species. The main part of the RA was formed by fine roots, even though the differences appeared less distinct in comparison to RL. The maximum values of RA were found within the diameter class of $0.5-1 \mathrm{~mm}$. Compared to RL, the peak of RA tended to flatten in higher diameter classes.

\subsection{Root density and hydrological parameters}

Our analyses revealed few correlations between the root properties and the parameters of the mobile water in the soil. Pearson product-moment analysis identified four groups where the correlations were significant $(P<0.05)$. The first group shows the effect of the soil depth on $F, L$, bulk density and roots. With increasing soil depth, bulk density increased and the films of mobile water became thicker, while $L$ and the length, surface area and volume of roots decreased. The second group, the key points of the wcws, initial volumetric soil moisture $\theta_{\text {in }}$, maximum volumetric soil moisture $\theta_{\text {Max }}$ and the water content after the drainage $\theta_{\mathrm{F}}$ were closely correlated with each other. In particular $\theta_{\text {in }}$ vs. $\theta_{\mathrm{F}}$ exhibited a coefficient of correlation of $r=0.989$. The amplitude of drainage, $w_{s}$, was strongly affected by $L(r=0.925)$ and, to a minor degree, by $F(r=-0.571)$. Furthermore, an increasing root density resulted in an intensification of the drainage.

The largest group of parameters has to do with root distribution (RL, RA, RV), but the group also contains the maximum sum of contact lengths $L$ and the film thickness $F$ of mobile water. The length, surface area and volume of roots were all correlated with each other $(0.676 \leq r \leq 0.915)$. Furthermore, the contact length $L$ and the film thickness 

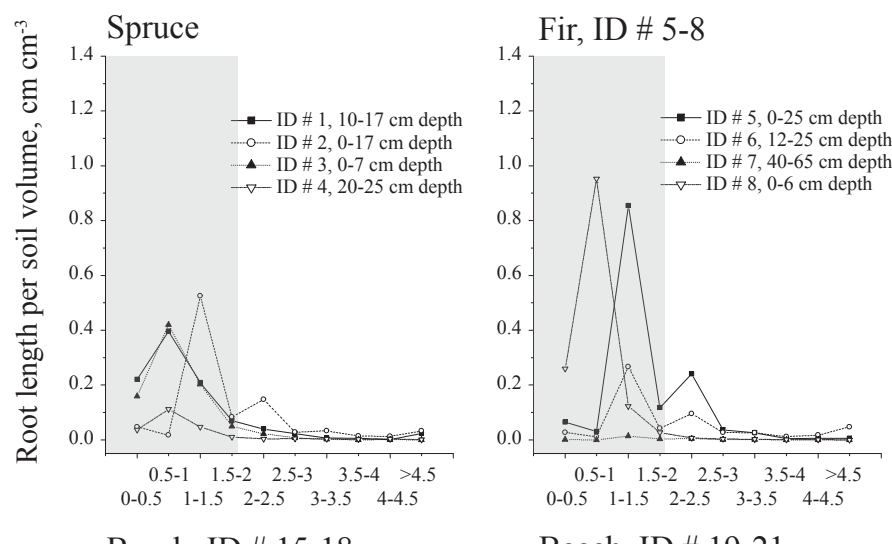

Beech, ID \# 19-21
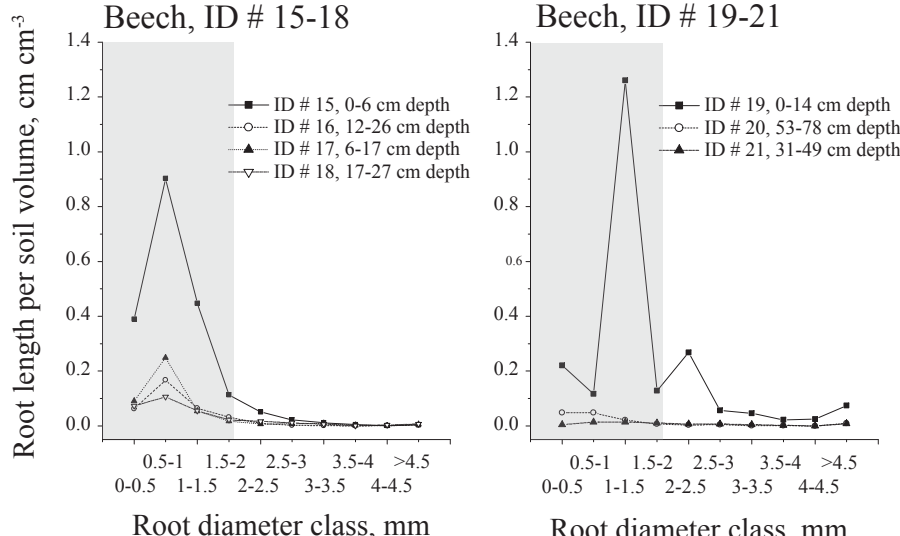

Root diameter class, $\mathrm{mm}$
Fir, ID \# 9-14

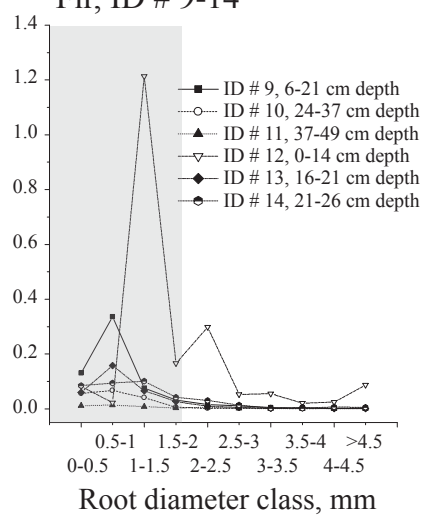

Fig. 4. Root length per soil volume of varying root diameter classes of the horizons where volumetric water content was measured. Depth in the legend refers to the depths where roots were separated. Grey shaded area: fine roots (diameter $\leq 2 \mathrm{~mm}$ ). ID\# according to Table 2 . To improve readability, the root lengths of trees at the fir and beech sites are shown separately in two different graphs.

$F$ were negatively correlated $(r=-0.745)$. The length, surface area and volume of roots affected the contact length $L$ and film thickness $F$ of mobile water. We found maximum correlations between contact length and RL $(r=0.892)$ and between film thickness and the root length $(r=-0.743)$. Bulk density affected root distribution, $F$ and $L$, but with $0.398 \leq|\mathrm{r}| \leq 0.738$ (modulus) the interrelations were less distinct than those between root length and $F$ and $L$. Table 3 presents the relationships between root parameters and preferential flow factors. Soil texture affected neither contact length $L$ nor film thickness $F$. The coefficients of determination between the percentage of sand, silt and clay, on the one hand and $F$ and $L$, on the other, varied from 0.03 to 0.16 . According to Eq. (2), the velocity of the wetting front should strongly correlate with $F$. Since we applied the arithmetic mean of the $N_{\mathrm{RE}}=10$ rivulet's film thicknesses as the quantity for the film thickness of a wcw, the correlation between $F$ and $v_{w}$ was only $r=0.787$, while the correlation between $v_{w}$ and the thickness of the first rivulet ensemble, which determines $t_{w}$ and hence $v_{w}$, was $r=0.973$.

The root lengths per soil volume of the 21 horizons were classified by applying a hierarchical cluster analysis (complete linkage, Euclidean distance). We determined the boundary among the groups at a Euclidian distance of 0.75 . That led to three clear clusters of RL (Fig. 5). The first group with 13 elements and the lowest root densities (RL $0.023-0.613 \mathrm{~cm} \mathrm{~cm}^{-3}$, arithmetic mean $0.28 \mathrm{~cm} \mathrm{~cm}^{-3}$ ) consisted of hydromorphic subsoil layers, with the exception of ID\# 10, 13, 16, 17 and 18, which were described as unaffected by stagnic or gleyic characteristics. Group two (RL $0.863-1.382 \mathrm{~cm} \mathrm{~cm}^{-3}$, arithmetic mean $1.11 \mathrm{~cm} \mathrm{~cm}^{-3}$ ) included non-hydromorphic subsoil horizons (ID\# 1, 8, 9), as well as topsoil layers (ID\# 2, 3). The third group (RL 1.944$2.216 \mathrm{~cm} \mathrm{~cm}^{-3}$, arithmetic mean $2.06 \mathrm{~cm} \mathrm{~cm}^{-3}$ ) was made up of topsoil layers without any hydromorphic properties.

The volumetric water content parameters $\theta_{\mathrm{in}}, \theta_{\mathrm{Max}}$ and $\theta_{\mathrm{F}}$, the volume flux density and velocities of wetting front $\left(v_{w}\right)$ did not differ among the three RL-groups. The average soil depth of RL-group 1 was significantly higher than that of either group 2 or 3 , while between groups 2 and 3 no statistical difference was verifiable. Regarding bulk density, there was a slight decrease from RL-group 1 to RL-group 3, but only groups $1-2$ and 1-3 were significantly different. The morphological properties of the roots were different in the three RL-groups. Both the surface areas and the volumes of roots increased with increasing root length $(P<0.05)$. The only 
Table 3. Matrix of Pearson product-moment correlation coefficients among water-flow determinants and root parameters.

\begin{tabular}{|c|c|c|c|c|c|c|c|c|c|c|c|c|c|}
\hline & Depth & $\theta_{\text {in }}$ & $\theta_{\text {Max }}$ & $\theta_{\mathrm{F}}$ & $w_{s}$ & $v_{w}^{\mathrm{a}}$ & $q$ & $L$ & $F$ & $\mathrm{RL}$ & RA & $\mathrm{RV}$ & BD \\
\hline Depth & 1.000 & & & & & & & & & & & & \\
\hline$\theta_{\text {in }}$ & 0.113 & 1.000 & & & & & & & & & & & \\
\hline$\theta_{\text {Max }}$ & -0.304 & $0.813^{* * * *}$ & 1.000 & & & & & & & & & & \\
\hline$\theta_{\mathrm{F}}$ & 0.143 & 0.989 *** & $0.796 * * *$ & 1.000 & & & & & & & & & \\
\hline$w_{S}$ & $-0.697 * * *$ & -0.298 & 0.297 & -0.342 & 1.000 & & & & & & & & \\
\hline$v_{w}^{\mathrm{a}}$ & 0.196 & $0.544^{*}$ & $0.484 *$ & $0.469 *$ & -0.116 & 1.000 & & & & & & & \\
\hline$q$ & 0.107 & 0.128 & 0.166 & 0.068 & 0.150 & $0.736 * * *$ & 1.000 & & & & & & \\
\hline$L$ & $-0.689 * * *$ & -0.403 & 0.160 & -0.429 & $0.925^{* * *}$ & -0.397 & -0.100 & 1.000 & & & & & \\
\hline$F$ & $0.757 * * *$ & 0.416 & 0.027 & 0.389 & $-0.571 * *$ & 0.787 *** & $0.567 * *$ & $-0.745^{* * * *}$ & 1.000 & & & & \\
\hline RL & $-0.701 * * *$ & -0.258 & 0.223 & -0.291 & $0.805^{* * *}$ & -0.404 & -0.127 & $0.892 * * *$ & $-0.743^{* * *}$ & 1.000 & & & \\
\hline RA & $-0.578 * *$ & -0.174 & 0.289 & -0.206 & $0.773 * * *$ & -0.304 & -0.041 & $0.839 * * *$ & $-0.610^{* *}$ & $0.915 * * *$ & 1.000 & & \\
\hline RV & -0.377 & -0.208 & 0.162 & -0.211 & $0.584 * *$ & -0.226 & -0.017 & $0.618^{* *}$ & $-0.460^{*}$ & $0.676 * * *$ & $0.881 * * *$ & 1.000 & \\
\hline $\mathrm{BD}$ & $0.711 * * *$ & 0.133 & -0.300 & 0.123 & $-0.659 * *$ & 0.451 & 0.329 & $-0.738 * * *$ & $0.738 * * *$ & $-0.688 * * *$ & $-0.605^{* *}$ & -0.398 & 1.000 \\
\hline
\end{tabular}

Depth: position of TDR-probe beneath soil surface; $\theta_{\text {in }}$ : initial volumetric soil moisture; $\theta_{\mathrm{Max}}$ : maximum volumetric soil moisture; $\theta_{\mathrm{F}}$ : volumetric water content after a drainage of $20 \mathrm{~h} ; w_{s}$ : difference between $\theta_{\mathrm{Max}}$ and $\theta_{\mathrm{F}} ; v_{w}$ : average velocity of wetting front; $q$ : volume flux density; $L$ : maximum sum of contact lengths between the mobile water and soil; $F$ : arithmetic mean of film thickness of mobile water; RL, RA, RV: length, surface area and volume of roots per soil volume; BD: Bulk density. Shading indicates significant correlation. $* \mathrm{P}<0.05, * * \mathrm{P}<0.01, * * * \mathrm{P}<0.001$, no appendix: not significant. ${ }^{\text {a }}$ Only 19 horizons were considered as $t_{w}=0$ in two cases.

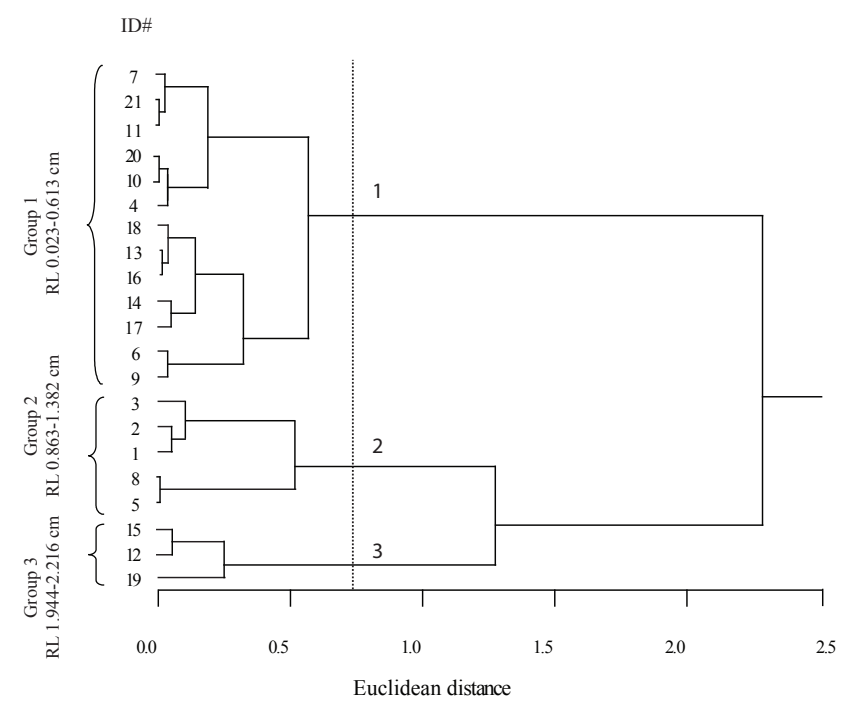

Fig. 5. Cluster analysis of root length per soil volume (RL) of the 21 layers where the wave-guides were installed (ID\# according to Table 2). Dashed line: Euclidean distance that separates the three RL groups.

exception was the root volume between groups 1-2 and 2-3 that was not significantly affected by root length, even though the average RV in group 3 was nearly twice that in group 2.

The preferential flow parameters $L$ and $F$ discriminated between the three groups. Contact length $L$ increased from RL-group 1 to 3 . The $L$ of group 1 achieved only 25 to 35 percent of the contact lengths of group 2 and 3 . Film thickness behaved inversely to the contact length: with increasing root length, $F$ decreased. Differences between groups 1-2 and 1-3 were significant at $P<0.05$. The difference between $\theta_{\text {Max }}$ and $\theta_{\mathrm{F}}, w_{s}$, rose with increasing RL. Significant differences in the mean values of $w_{s}$ were detected among RL-groups 1-2 and 1-3, while the $w_{s}$ of 2-3 were not dis- tinguishable from each other. Figure 6 shows how the soil, root and preferential flow properties of the three RL-groups varied.

As Table 3 and Fig. 6 demonstrate, the root length RL, contact length $L$ and film thickness $F$ are related to each other. Figure 7 illustrates this relation. Table 3 shows that the coefficients of correlation, $\mathrm{r}$, between RL and $L$, and between RL and $F$ exceeded 0.74 with a significance level of $P<0.001$. The regression equations between $L$ and RL, and between $F$ and RL, respectively, are given by

$F=-4.043 \mathrm{RL}+12.562$

$L=9.823 \mathrm{RL}+1.590$

The contact length $L$ increases with increasing root length per soil volume while film thickness $F$ decreases. The subsoil layers (group 1, Fig. 5) are characterised by low root densities, short contact lengths and considerable film thicknesses. By contrast, the non-hydromorphic topsoil horizons (group 3) exhibit the highest values of root lengths and contact lengths, but the smallest film thicknesses. Group 2 is positioned between groups 1 and 3 with intermediate root lengths, contact lengths and film thicknesses.

\section{Applications}

Film thickness and contact length are basic parameters of rivulet flow, while volume flux density, mobile water content and velocities of drainage and wetting fronts (Eqs. 1 to 11) are related to $F$ and $L$. Contact length and film thickness are significantly related to root density (Fig. 7). Thus preferential infiltration can be modelled on the basis of root densities. $L$ and $F$ are estimated with RL, applying the equations of the regression lines between RL and $L$ and $F$, respectively 

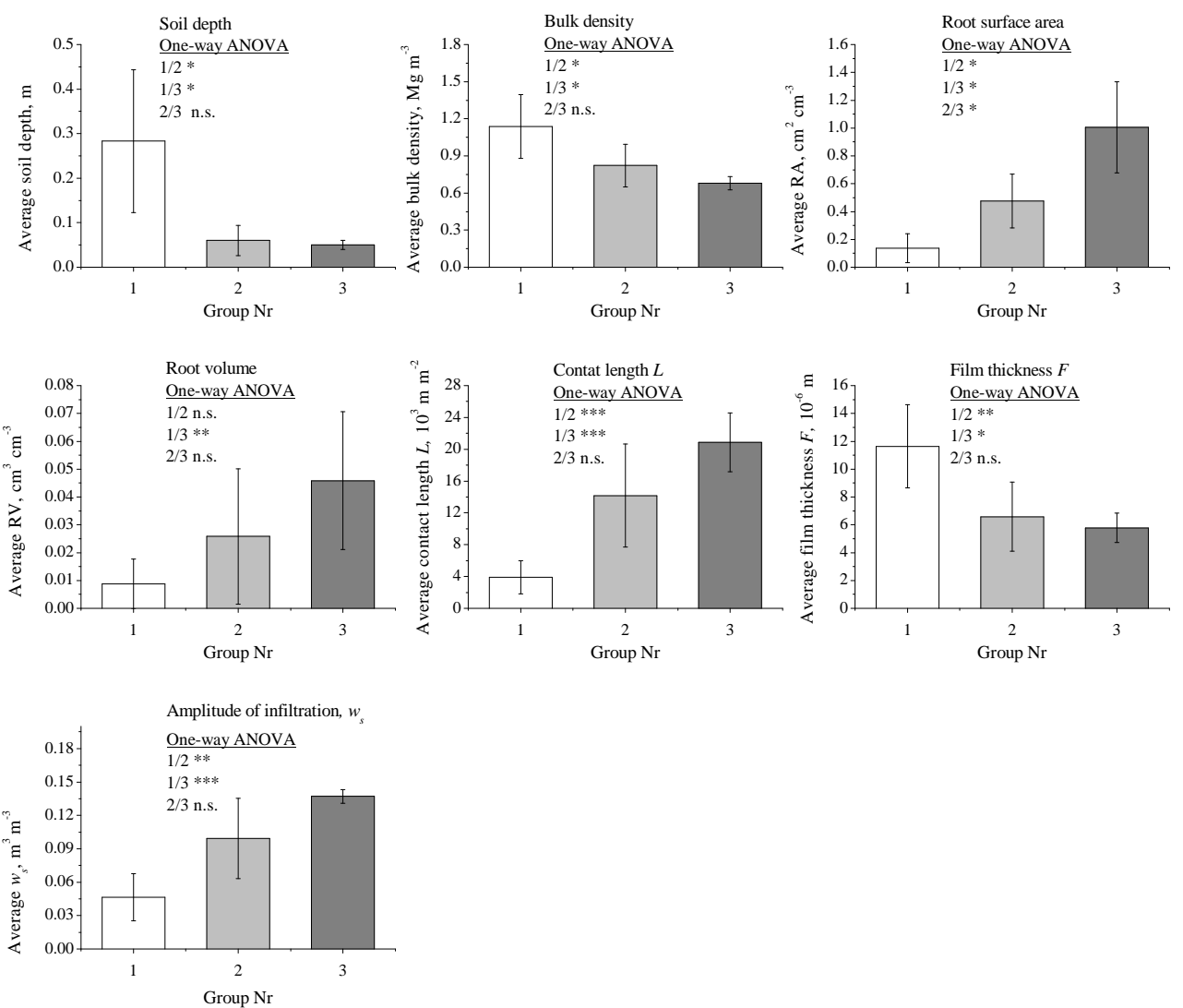

Fig. 6. Soil, root and preferential flow parameters of the three root length groups. White column: group $1\left(\mathrm{RL} 0.023-0.613 \mathrm{~cm} \mathrm{~cm}^{-3}\right)$, grey column: group 2 (RL $0.863-1.382 \mathrm{~cm} \mathrm{~cm}^{-3}$ ), dark grey column: group 3 (RL $1.944-2.216 \mathrm{~cm} \mathrm{~cm}^{-3}$ ). Probability levels for the one-way ANOVA: $* P<0.05, * * P<0.01, * * * P<0.001$, n.s. not significant. Bars indicate standard error.

(Eqs. 13, 14). Input data for our model were root densities, while output data were the corresponding water content waves and therefore $\theta_{\mathrm{Max}}, \theta_{\mathrm{F}}$, volume flux densities $q$, velocities of water and drainage fronts as well as $w_{s}$. For our example, we modelled five water content waves based on root densities of $0.25,0.5,1,1.5$, and $2 \mathrm{~cm}$ per $\mathrm{cm}^{3}$ soil. We assume in what follows that all rivulet ensembles move with the same velocity, and that the modelled wcw moves with a sharp wetting-shock front. Table 4 shows the resulting $L, F$, $w_{s}, v_{w}$ and $q$.

The parameters of the modelled water content waves were defined as follows: duration of irrigation $(70 \mathrm{~mm} / \mathrm{h})$ was $3600 \mathrm{~s}$, starting at $t=0$. The contact length of the rivulets corresponds to the maximum sum of contact lengths $L$ (Eq. 14) of the associated root densities. The film thicknesses of the rivulets were determined according to Eq. (13) (arithmetic mean of film thickness). Equation (1) was adapted to obtain the water content of the rivulet. The arrival time of the wetting front $\left(t_{w}\right)$ at a depth of $0.15 \mathrm{~m}$ follows from Eq. (4), while Eq. (5) yields the arrival time of the drainage front. The water content waves were modelled with a time resolution of $100 \mathrm{~s}$, starting at -800 and ending at $75000 \mathrm{~s}$. The applica- tion of Eq. (11) led to the trailing waves. Figure 8 shows the modelled wcws.

The pathways of the five water content curves vary, especially with regard to the maximum water content $\theta_{\mathrm{Max}}$ $\left(0.046 \leq \theta_{\mathrm{Max}} \leq 0.106\right)$. A root density of $1.5 \mathrm{~cm} \mathrm{~cm}^{-3}$ resulted in the maximum content of mobile water. The amplitude of the drainage $w_{s}$ is maximal at a RL of 1.0 to $1.5 \mathrm{~cm} \mathrm{~cm}^{-3}$. If the root densities were higher or lower, the amplitude of the drainage was reduced by 10 to 65 percent. The lowest value of $\theta_{\mathrm{Max}}$, and therefore of $w_{s}$, was reached at a root density of $0.25 \mathrm{~cm} \mathrm{~cm}^{-3}$. $\theta_{\mathrm{F}}$ increased with increasing RL, but with $0.002 \leq \theta_{\mathrm{F}} \leq 0.010$, the differences fall below $1 \%$ water content. The volume flux density $q$, determined by Eq. (3), exhibits its maximum value at lower root densities $\left(0.5 \mathrm{~cm} \mathrm{~cm}^{-3}\right)$ than the mobile water content parameters $\theta_{\mathrm{Max}}$ and $\theta_{\mathrm{F}}\left(1.5 \mathrm{~cm} \mathrm{~cm}^{-3}\right)$. Above a root density of $0.5 \mathrm{~cm} \mathrm{~cm}^{-3}, q$ decreased. The peak value exceeded the minimum volume flux density by a factor of about 5 . $F$ decreased with increasing RL, so that $v_{w}$ decreased with increasing RL (Table 4). Figure 9 serves to illustrate the hydrological properties of the modelled wcws with different root densities. 
Table 4. Components of water flow of the modelled water content waves.

\begin{tabular}{llllll}
\hline Root density $\mathrm{cm} \mathrm{cm}^{-3}$ & $\begin{array}{l}L \\
\mathrm{~m} \mathrm{~m}^{-2}\end{array}$ & $\begin{array}{l}F \\
\mu \mathrm{m}\end{array}$ & $\begin{array}{l}w_{s} \\
\mathrm{~m}^{3} \mathrm{~m}^{-3}\end{array}$ & $\begin{array}{l}v_{w} \\
\mathrm{~mm} \mathrm{~s}^{-1}\end{array}$ & $\begin{array}{l}q \\
10^{-6} \mathrm{~m} \mathrm{~s}^{-1}\end{array}$ \\
\hline 0.25 & 4045 & 11.6 & 0.047 & 0.44 & 20.4 \\
0.5 & 6501 & 10.5 & 0.069 & 0.36 & 24.9 \\
1 & 11412 & 8.5 & 0.097 & 0.24 & 23.1 \\
1.5 & 16323 & 6.5 & 0.106 & 0.13 & 14.7 \\
2.0 & 21235 & 4.5 & 0.095 & 0.07 & 6.2 \\
\hline
\end{tabular}

$L$ : maximum sum of contact lengths between mobile water and soil; $F$ : arithmetic mean of film thickness of mobile water; $w_{s}$ : decrease in soil moisture during a $20 \mathrm{~h}$ drainage; $v_{w}$ : average velocity of wetting front; $q$ : volume flux density.

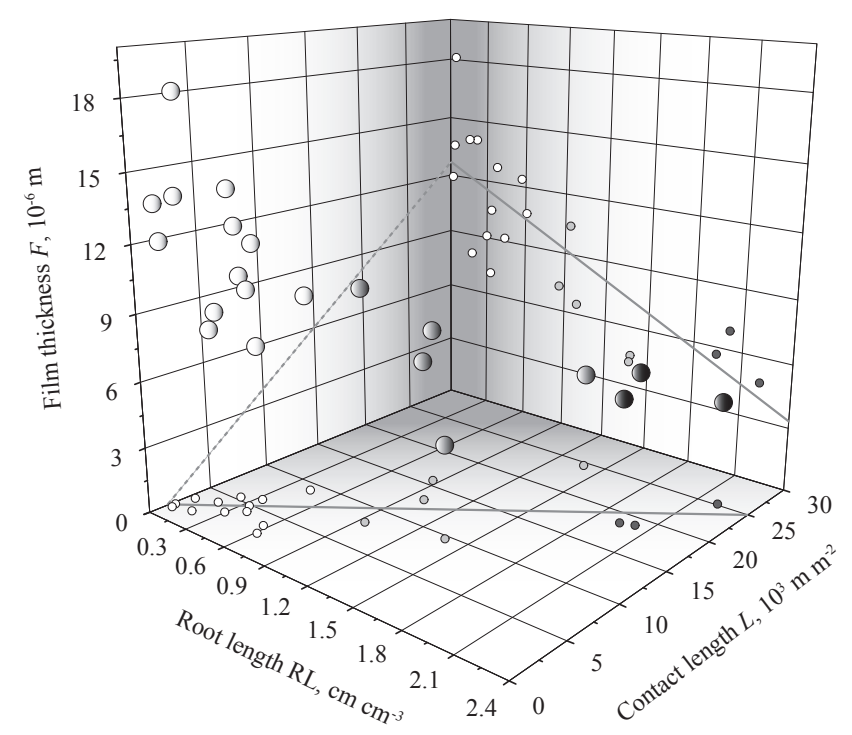

Fig. 7. Relationship between root length per soil volume RL, maximum sum of contact lengths $L$ and arithmetic mean of film thickness $F$ of mobile water. Large balls: data points in XZYspace; small circles: data projections on XY- and XZ-plane. White: RL-group 1, grey: RL-group 2, dark grey: RL-group 3 (Fig. 5). Grey lines: linear correlation between root length RL and contact length $L(L=9.823 \mathrm{RL}+1.590)$, root length $\mathrm{RL}$ and film thickness $F(F=-4.043 \mathrm{RL}+12.562)$. Dashed grey line: cutting line of the regression plane and the YZ-plane.

Assuming a constant root density over a soil depth of $0.5 \mathrm{~m}$, the minimum potential water storage capacity can be calculated on the basis of the amplitude of drainage $\left(w_{s}\right)$. After $20 \mathrm{~h}$ of drainage, a root density of $0.25 \mathrm{~cm} \mathrm{~cm}^{-3}$ soil leads to a potential minimum water storage capacity of $24 \mathrm{~mm}$, and a RL of $1 \mathrm{~cm} \mathrm{~cm}^{-3}$ to $53 \mathrm{~mm}$. As a result, the soil with the higher root density should be able to store the amount of water produced during one hour of heavy precipitation with a return period of approximately 100 years, while the site with a quarter of the root density could store only the water produced during one hour of heavy precipitation with a 2-year return period.

\section{Discussion}

Perillo et al. (1999) maintained that tree roots, both decayed and alive, appeared to be the most important initiators for preferential flow path, but they pointed out that not all roots were necessarily associated with preferential flow paths. These findings are also consistent with our results, where no clear relation between root length distribution and the probability of the appearance of preferential flow could be found. This lack of coherence may be due to the large number of parameters involved in infiltration, such as water content (Germann et al., 2007), hydrophobicity (Wang et al., 2000), open burrows and horizon boundaries (Perillo et al., 1999). In addition, we only recorded root length densities. They do not describe the connectivity of pores formed by the roots.

Our results support the hypothesis that tree roots are a key factor in preferential infiltration in gleyic soils with stagnic properties, or are at least linked to preferential flow parameters according to Germann et al. (2007). We showed that the sum of contact lengths $L$, and to a lesser extent the arithmetic mean of film thickness $F$, which are the basic units of mobile water in preferential infiltration, were related to root densities. With increasing soil depth, and therefore bulk density, $F$ increased and $L$ decreased. It must be assumed that, in topsoil horizons, high root densities result in a densely branched network of pores. Thus water flows in thin films, but the contact length between the mobile water and the soil is large. This finding is also supported by Flury et al. (1994), who studied infiltration patterns using dye experiments. In their case, the dye spread through the uppermost five to ten centimetres of topsoil completely. With a lower root density fewer pores are likely as it is generally accepted that roots generate macropores (e.g. Devitt and Smith, 2002). Thus the potential contact area between mobile water and soil is reduced and the film thickness of mobile water increased, resulting in an acceleration of the water (Eq. 2) comparable to the water flow through a funnel. This effect is more pronounced at greater soil depth. 

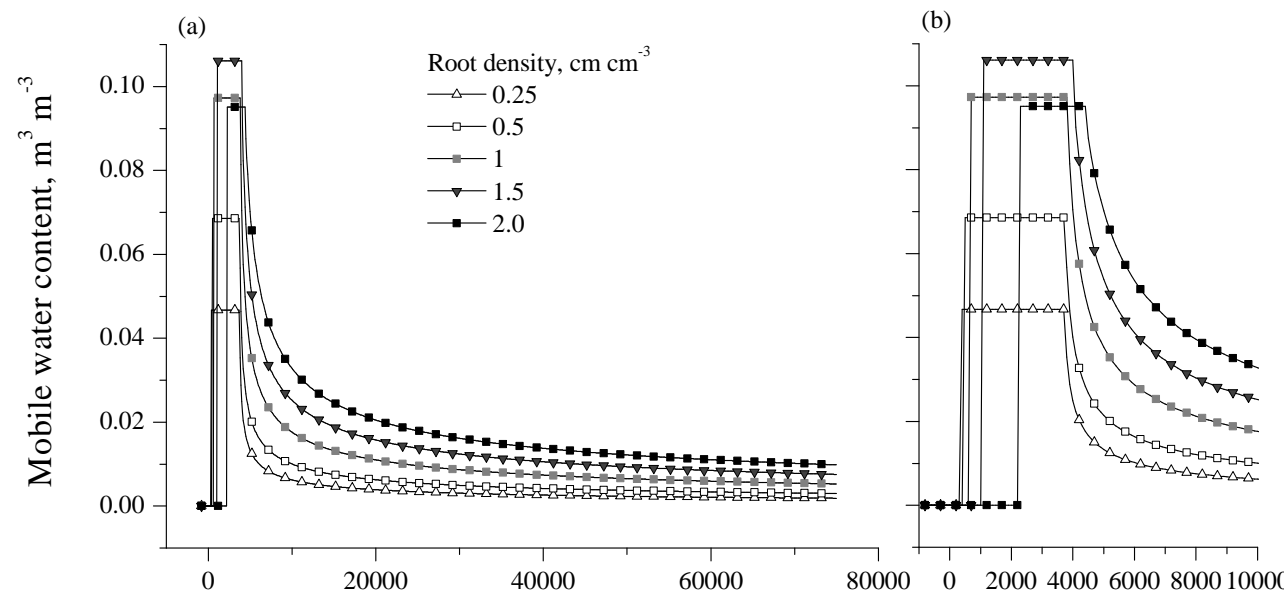

Time since irrigation began, $\mathrm{s}$

Fig. 8. Modelled water content waves of different root densities at a depth of $15 \mathrm{~cm}$. (a): $1 \mathrm{~h}$ irrigation and subsequent drainage, (b): first $10000 \mathrm{~s}$ of the irrigation and subsequent drainage. Duration of irrigation: $3600 \mathrm{~s}$, starting at $t=0$.

Genenger et al. (2003) found fine root length densities of approximately $0.6,1.0$ and $1.0 \mathrm{~cm} \mathrm{~cm}^{-3}$ in in-growth cores after $1,1.5$ and 2 years in the topsoil of a spruce-dominated forest stand in Switzerland. These densities are comparable to the topsoils' root densities of 0.44 to $2.21 \mathrm{~cm} \mathrm{~cm}^{-3}$ at our study site. Alaoui and Helbling (2006) stated that macropore volumes in topsoils represented only 2.00 and $0.23 \%$ of the total soil volume, but transported approximately 100 and $74 \%$ of the entire mobile water. This demonstrates that bulk density, which is mainly determined by the material that surrounds the flow channels, can be ignored with respect to our hydraulic characterisation of the preferential flow path. The root volume of the horizons investigated in this study accounted for 0.05 to $6.5 \%$ (median $0.78 \%$ ) of the total soil volume. Assuming that water flowed along roots and root channels, as Jørgensen et al. (2002) claim, the root volumes we found are comparable to the macropore volume as described by Alaoui and Helbling (2006).

Tree roots seem to be particularly clearly associated with the contact length. Film thickness is presumably not only determined by RL but is also a response to the spatial distribution of pores via the soil depth and the pore geometry. The slope of the correlation line between RL and $L$ is approximately 2.5 times greater than the correlation line between $\mathrm{RL}$ and $F$, which indicates that an increase in RL influences $L$ more than $F$. For example, a doubling of RL from 0.5 to $1 \mathrm{~cm}^{2} \mathrm{~cm}^{3}$ soil leads to a $76 \%$ increase in $L$, but only a $19 \%$ reduction in $F$. As a result, a shifting of RL modifies $L$ to a greater degree than $F$.

The application of the rivulet approach has shown that a root density of approximately 1 to $1.75 \mathrm{~cm} \mathrm{~cm}^{-3}$ resulted in the highest $\theta_{\text {Max }}$ and $w_{s}$. Lower root densities led to a strong decrease in the contact lengths and increased film thicknesses. Above a RL of $2.0 \mathrm{~cm} \mathrm{~cm}^{-3}$, the films became so

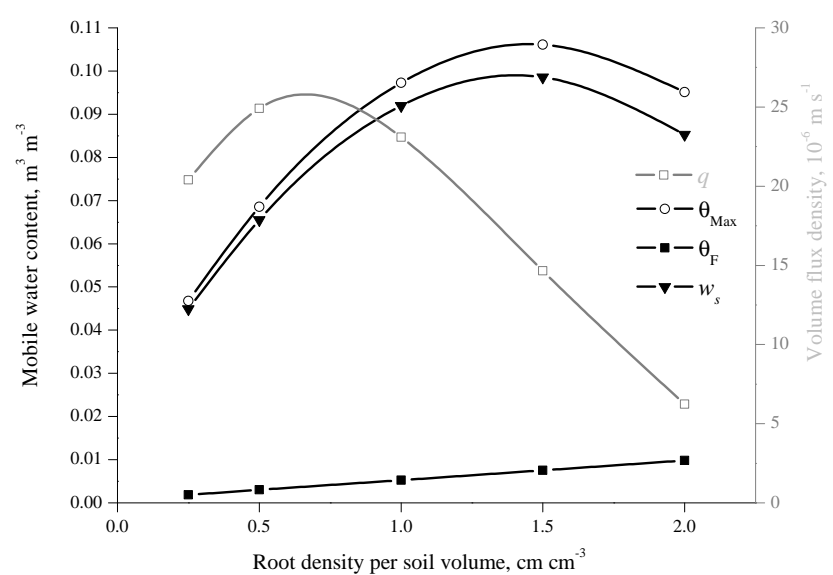

Fig. 9. Hydrological properties of modelled trailing waves with different root densities. $\theta_{\mathrm{Max}}$ : maximum volumetric soil moisture; $\theta_{\mathrm{F}}$ : volumetric water content after a drainage of $20 \mathrm{~h} ; w_{s}$ : difference between $\theta_{\text {Max }}$ and $\theta_{\mathrm{F}} ; q$ : volume flux density.

thin that the limit for the occurrence of preferential flow was reached. Since volume flux density is a function of the product of $F^{3}$ and $L$, the peak value of $q$ was reached at lower root densities $\left(\approx 0.5 \mathrm{~cm} \mathrm{~cm}^{-3}\right)$ than $\theta_{\text {Max }}$ and $w_{s}$. To achieve maximum volume flux density and maximum drainage after the irrigation, approximately $1 \mathrm{~cm}$ roots per $\mathrm{cm}^{-3}$ soil appear to be the ideal root density. Only seven non-hydromorphic topsoil horizons of the 21 investigated layers had a root density between 0.5 and $1.5 \mathrm{~cm} \mathrm{~cm}^{-3}$. Three topsoil layers exceeded this value, and 11 horizons, with one exception hydromorphic subsoil layers, had less than $0.5 \mathrm{~cm}$ roots per $\mathrm{cm}^{-3}$ soil. 
Soil structure was considered only marginally in this study, even though it can affect water transport in soils (Kodešová et al., 2009). As mentioned above, the soil structure of the investigated horizons was mainly blocky (17 out of 21 layers). Nevertheless, our approach did not allow us to distinguish between the influence of the structures and the roots on water infiltration. As it has been shown by many authors, root morphology and soil structure depend on one another in many intricate ways. Roots and other soil organisms affect soil structure, but the structure also influences root growth (Angers and Caron, 1998). Materechera et al. (1994) showed that roots create pores, but could also fragment soil aggregates through penetration. These findings indicate that it is impossible to specify all preferential flow paths by means of root measurements. It has been shown that cracks adjacent to living alfalfa roots have only a temporary effect, while decaying roots produce stable macropores (Mitchell et al., 1995). Noguchi et al. (1997) pointed out that at least $70 \%$ of the macropores $(\geq 2 \mathrm{~mm})$ in the topsoil and $55 \%$ in the subsoil in a forest soil in Japan were associated with roots. Hagedorn and Bundt (2002) showed that preferential flow paths in a structured forest soil persist for decades. Beven and Germann (1982) observed that macropores formed from tree roots may persist for at least $50-100$ years. The turnover rates of fine roots from spruce, fir and beech were determined as approximately $0.7,1.1$ and 0.6 year $^{-1}$, respectively (Withington et al., 2006). These observations indicate how important tree roots are for the formation of preferential flow paths. Forest managers may be able to influence roots and root distributions, and thus infiltration properties, indirectly through selecting e.g. species, tree densities or forest age structures. These are much easier to plan and manage than soil structure directly.

This study has contributed to a better understanding of the significance of roots for preferential flow in soils comparable to those in the investigated area by showing how the basic properties of preferential flow, film thickness and contact length of mobile water are linked to the density of root length. We have thus been able to show that root distributions represent the pore system that carries preferential infiltration.

\section{Conclusions}

We have provided evidence that root length distribution is a key factor for infiltration. The basic properties of preferential infiltration, contact length $L$ and film thickness $F$ are closely related to root density. We found a positive correlation between RL and $L$, but a negative relation between RL and $F$. This indicates that a larger root density does not necessarily result in an intensification of preferential infiltration.

With increasing soil depth, rivulets of preferential infiltration become thicker, but the contact lengths between soil and mobile water become shorter. As a result, preferential flow in topsoil horizons is characterised by numerous thin water films, while rivulets in subsoil horizons are thicker but less frequent. Since RL and $F$ and $L$ are closely related, it was possible to model water content waves during an irrigation and subsequent drainage based on root densities. We showed that the rise in the water content during irrigation and subsequent fall during drainage within $20 \mathrm{~h}$ was at a maximum at a root density of approximately 1 to $1.5 \mathrm{~cm} \mathrm{~cm}^{-3}$, while volume flux density $q$ achieved its peak value at a root density of $0.5 \mathrm{~cm} \mathrm{~cm}^{-3}$.

To maximise the impact of preferential flow path for flood retention in hydromorphic forest soils, we propose a root density of about $1 \mathrm{~cm} \mathrm{~cm}^{-3}$. Our investigations have shown that a root density between 0.5 and $1.5 \mathrm{~cm} \mathrm{~cm}^{-3}$ was reached only in non-hydromorphic topsoil layers to a depth of approximately $20 \mathrm{~cm}$. The cultivation of deep-rooting tree species improves the root density in the subsoil and therefore stimulates preferential infiltration into deeper, hydromorphic horizons and enlarges the potential soil volume accessible to surface water.

Acknowledgements. We thank Philipp Mösch and Dieter Müller for permission to conduct our studies in their forest district and Roger Köchli for his help in the field. We are grateful to Abdallah Alaoui, Marco Carizzoni and Ingrid Hincapié from the University of Bern for their instruction in using the TDR-technique and the sprinkler device, and Silvia Dingwall and Barbara Lange for improving our English. This study was supported by the COST Action E38 (Woody Root Processes).

Edited by: G. H. de Rooij

\section{References}

Alaoui, A. and Goetz, B.: Dye tracer and infiltration experiments to investigate macropore flow, Geoderma, 144, 279-286, 2008.

Alaoui, A. and Helbling, A.: Evaluation of soil compaction using hydrodynamic water content variation: Comparison between compacted and non-compacted soil, Geoderma, 134, 97-108, 2006.

Angers, D. A. and Caron, J.: Plant-induced changes in soil structure: Processes and feedbacks, Biogeochemistry, 42, 55-72, 1998.

Badoux, A., Witzig, J., Germann, P. F., Kienholz, H., Lüscher, P., Weingartner, R., and Hegg, C.: Investigations on the runoff generation at the profile and plot scales, Swiss Emmental, Hydrol. Process., 20, 377-394, 2006.

Beschta, R. L., Pyles, M. R., Skaugset, A. E., and Surfleet, C. G.: Peakflow responses to forest practices in the western cascades of Oregon, USA, J. Hydrol., 233, 102-120, 2000.

Beven, K. and Germann, P.: Macropores and water flow in soils, Water Resour. Res., 18, 1311-1325, 1982.

Bouma, J.: Influence of soil macroporosity on environmental quality, Adv. Agron., 46, 1-37, 1991.

Cheng, J. D., Lin, L. L., and Lu, H. S.: Influences of forests on water flows from headwater watersheds in Taiwan, For. Ecol. Manage., 165, 11-28, 2002.

Cognard-Plancq, A.-L., Marc, V., Didon-Lescot, J.-F., and Normand, M.: The role of forest cover on streamflow down sub- 
Mediterranean mountain watersheds: a modelling approach, J. Hydrol., 254, 229-243, 2001.

Demontzey, P.: Etude sur les travaux de reboisement et de gazonnement des montagnes, Imprimerie Nationale, Paris, 1878.

Devitt, D. A. and Smith, S. D.: Root channel macropores enhance downward movement of water in a Mojave Desert ecosystem, J. Arid Environ., 50, 99-108, 2002.

Di Pietro, L., Ruy, S., and Capowiez, Y.: Predicting preferential water flow in soils by traveling-dispersive waves, J. Hydrol., 278, 64-75, 2003.

Ellenberg, H. and Klötzli F.: Waldgesellschaften und Waldstandorte der Schweiz, Mitteilungen EAFV, 48, 587-930, 1972.

Engler, A.: Untersuchungen über den Einfluss des Waldes auf den Stand der Gewässer, Mitteilungen der Schweizerischen Zentralanstalt für das forstliche Versuchswesen, XII Band, 1919.

FAO-Unesco: Soil map of the world, ISRIC, Wageningen, 1994.

Federal Office for the Environment (FOEN): http://www. hydrodaten.admin.ch/d/2179.htm, last access: 16 May, 2008.

Flury, M., Flühler, H., Jury, W. A., and Leuenberger, J.: Susceptibility of soils to preferential flow of water: A field study, Water Resour. Res., 30, 1945-1954, 1994.

Gärdenäs, A. I., Šimnek, J., Jarvis, N., and van Genuchten, M. T.: Two-dimensional modelling of preferential water flow and pesticide transport from a tile-drained field, J. Hydrol., 329, 647-660, 2006.

Genenger, M., Zimmermann, S., Hallenbarter, D., Landolt, W., Frossard, E., and Brunner, I.: Fine root growth and element concentrations of Norway spruce as affected by wood ash and liquid fertilisation, Plant Soil, 255, 253-264, 2003.

Gerke, H. H.: Preferential flow descriptions for structured soils, J, Plant Nutr. Soil Sci., 169, 382-400, 2006.

Germann, P. F. and Beven, K.: Kinematic wave approximation to infiltration into soils with sorbing macropores, Water Resour. Res., 21, 990-996, 1985.

Germann, P., Helbling, A., and Vadilonga, T.: Rivulet approach to rates of preferential infiltration, Vadose Zone J., 6, 207-220, 2007

Germann, P. F. and Hensel D.: Poiseuille flow geometry inferred from velocities of wetting fronts in soils, Vadose Zone J., 5, 867876, 2006.

Gish, T. J., Gimenez, D. and Rawls, W. J.: Impact of roots on ground water quality, Plant Soil, 200, 47-54, 1998.

Hagedorn, F. and Bundt, M.: The age of preferential flow paths, Geoderma, 108, 119-132, 2002.

Hegg, C., Thormann, J.-J., Böll, A., Germann, P., Kienholz, H., Lüscher, P., and Weingartner, R.: Lothar und Wildbäche. Schlussbericht eines Projektes im Rahmen des Programms "Lothar Evaluations- und Grundlagenprojekte", Eidgenössische Forschungsanstalt WSL, Birmensdorf, 2004.

Jørgensen, P. R., Hoffmann, M., Kistrup, J. P., Bryde, C., Bossi, R., and Villholth, K. G.: Preferential flow and pesticide transport in a clay-rich till: Field, laboratory, and modeling analysis, Water Resour. Res., 38, 1246, doi:10.1029/2001WR000494, 2002.

Kawamoto, K., Mashino, S., Oda, M., and Miyazaki, T.: Moisture structures of laterally expanding fingering flows in sandy soils, Geoderma, 119, 197-217, 2004.
Kodešová, R., Vignozzi, N., Rohošková, M., Hájková, T., Koárek, M., Pagliai, M., Kozák, J., and Šimnek, J.: Impact of varying soil structure on transport processes in different diagnostic horizons of three soil types. J. Contam. Hydrol., 104, 107-125, 2009.

Kung, K.-J. S.: Preferential flow in a sandy vadose zone: 2 . Mechanism and implications, Geoderma, 46, 59-71, 1990.

Li, Y. and Ghodrati, M.: Preferential transport of nitrate through soil columns containing root channels, Soil Sci. Soc. Am. J., 58, 653-659, 1994.

Mapa, R. B.: Effect of reforestation using Tectona grandis on infiltration and soil water retention, For. Ecol. Manage., 77, 119-125, 1995.

Materechera, S. A., Kirby, J. M., Alston, A. M., and Dexter, A. R. Modification of soil aggregation by watering regime and roots growing through beds of large aggregates, Plant Soil, 160, 5766, 1994.

Mitchell, A. R., Ellsworth, T. R., and Meek, B. D.: Effect of root systems on preferential flow in swelling soil, Commun. Soil Sci. Plant Anal., 26, 2655-2666, 1995.

Noguchi, S., Tsuboyama, Y., Sidle, R. C., and Hosoda, I.: Spatially distributed morphological characteristics of macropores in forest soils of Hitachi Ohta Experimental Watersheds, Japan, J. For. Res., 2, 207-215, 1997.

Perillo, C. A., Gupta, S. C., Nater, E. A., and Moncrief, J. F.: Prevalence and initiation of preferential flow paths in a sandy loam with argillic horizon, Geoderma, 89, 307-331, 1999.

Polomski, J. and Kuhn, N.: Wurzelsysteme, Haupt, Bern, Stuttgart, Wien, 1998.

Roth, K., Schulin, R., Flühler, H., and Attinger, W.: Calibration of time domain reflectometry for water content measurements using a composite dielectric approach, Water Resour. Res., 26, $2267-$ 2274, 1990.

Soil survey division staff: Soil survey manual, Soil Conservation Service, U.S. Department of Agriculture, Handbook 18, 1993.

Tremblay, Y., Rousseau, A. N., Plamondon, A. P., Lévesque, D., and Jutras, S.: Rainfall peak flow response to clearcutting 50\% of three small watersheds in a boreal forest, Montmorency Forest, Québec, J. Hydrol., 352, 67-76, 2008.

Wang, Z., Wu, Q. J., Wu, L., Ritsema, C. J., Dekker, L. W., and Feyen, J.: Effects of soil water repellency on infiltration rate and flow instability, J. Hydrol., 231-232, 265-276, 2000.

Weiler, M. and Naef, F.: An experimental tracer study of the role of macropores in infiltration in grassland soils, Hydrol. Process., 17, 477-493, 2003

Withington, J. M., Reich, P. B., Oleksyn, J., and Eissenstat, D. M.: Comparisons of structure and life span in roots and leaves among temperate trees, Ecol. Monogr., 76, 381-397, 2006.

Zimmermann, S., Luster, J., Blaser, P., Walthert, L. and Lüscher, P.: Waldböden der Schweiz. Band 3. Region Mittelland und Voralpen, Eidgenössische Forschungsanstalt WSL, Birmensdorf, Hep Verlag, Bern, 2006. 